University for Business and Technology in Kosovo

UBT Knowledge Center

UBT International Conference

2017 UBT International Conference

Oct 28th, 11:00 AM - 12:30 PM

\title{
The UBT Knowledge Center: A Collaborative Design Approach
}

\author{
Edmond Hajrizi \\ University for Business and Technology, ehajrizi@ubt-uni.net
}

Mary M. Somerville

University of the Pacific, msomerville@pacific.edu

Anita Mirijamdotter

Linnaeus University, anita.mirijamdotter@Inu.se

Follow this and additional works at: https://knowledgecenter.ubt-uni.net/conference

Part of the Education Commons

\section{Recommended Citation}

Hajrizi, Edmond; Somerville, Mary M.; and Mirijamdotter, Anita, "The UBT Knowledge Center: A Collaborative Design Approach" (2017). UBT International Conference. 109.

https://knowledgecenter.ubt-uni.net/conference/2017/all-events/109

This Event is brought to you for free and open access by the Publication and Journals at UBT Knowledge Center. It has been accepted for inclusion in UBT International Conference by an authorized administrator of UBT Knowledge Center. For more information, please contact knowledge.center@ubt-uni.net. 


\title{
The UBT Knowledge Center: A Collaborative Design Approach
}

\author{
Edmond Hajrizi ${ }^{1}$, Mary M. Somerville ${ }^{2}$, Anita Mirijamdotter ${ }^{3}$ \\ ${ }^{1}$ UBT-Higher Education Institution, Lagjja Kalabria, 10000 n.n., Prishtina, Kosovo \\ ${ }^{2}$ University of the Pacific, Stockton, California, USA, \\ ${ }^{3}$ Linnaeus University, Växjö, Sweden \\ ehajrizi@ubt-uni.net ${ }^{1}$
}

\begin{abstract}
In setting the institutional vision for University for Business and Technology in 2001, founder Dr. Edmond Hajrizi sought to educate Kosovo students to become active contributors to the society and in the workplace, within the country, the Balkans region, and beyond. The UBT Knowledge Center initiative extends the founding vision of national development through higher education. Since local knowledge, identity, and learning are necessarily situated, Kosovar students, faculty, staff, and administrators serve as topical experts and international educators from Sweden and the United States serve as design facilitators for this collaborative project. This paper presents the vision for and concept of the Knowledge Center, followed by reflections on the process so far and anticipated future actions.
\end{abstract}

Keywords: Constructive pedagogy, Flipped classroom, Informed learning, Informed systems approach, Soft systems methodology

\section{Introduction}

Collaborative design commenced in April 2017 when international faculty from Sweden and the United States co-taught a graduate level course, Information Systems Analysis, Design, and Modelling, at the Pristina campus. Working with UBT administrators, directors, managers, and librarians, students worked in teams to co-design three essential parts of a holistic Knowledge Center ecosystem: a digital environment to advance local knowledge visibility, an organizational environment to enhance boundary crossing collaboration, and a digital academic library environment to enable discovery of and access to published academic scholarship.

Following these 'learn by doing' instructional activities, exploratory knowledge management discussions produced a Knowledge Center concept paper in July 2017, with funding from the Fulbright Specialist Program. The white paper recognizes the social context of learning - that knowledge is acquired and understood through action, interaction, and sharing with others. It thereby anticipates the social relationships necessary for information exchange and knowledge creation, oftentimes enabled by technology, for knowledge incubation in the university and beyond [12].

This collaborative design approach anticipates continuing to convene multidisciplinary conversations and to integrate interdisciplinary coursework into realization of the University's 
founding knowledge vision which recognizes the critical importance of developing new and more complex ways for connecting people, information, and technology in the university and with the society. In response, the UBT Knowledge Center aims to foster knowledge creation which curates and preserves intellectual, cultural, national, and regional resources for future generations.

\section{Knowledge Center Vision}

The University for Business and Technology Knowledge Center furthers awareness and usage of existing knowledge for exchange and creation of more knowledge. Online 'anytime, anyplace' access to local and global knowledge collections enables UBT researchers to harvest the best ideas available from the core academic publisher databases and a curated UBT digital repository. The increasingly digital landscape, in turn, offers rich opportunities for redirecting University fiscal, human, and facility resources.

Of special importance, an institutional repository makes 'local knowledge visible' - through discovery and access - to University student, faculty, and staff scholarship and creative work. Over time and with practice, students' assignment workflows will naturally identify earlier projects and reports on their subjects of interest. This faculty and student work could also be designated as open access, thereby ensuring worldwide dissemination of a growing corpus of UBT thought. Substantial Albanian language content ensures relevance to Kosovar community readers and fortifies UBT's lead role in national and regional knowledge generation.

Within this enriched digital knowledge ecosystem, University library facilities provide gathering spaces designed to foster diverse learning activities, ranging from reflective study to collaborative work. The transition from a traditional book warehouse function to a catalytic knowledge incubation purpose necessarily requires reconsidering information systems and facility design assumptions. So, well aligned with its signature 'learn by doing' approach, University for Business and Technology employs an inclusive design approach to establish shared vision, purpose, and methods "to build collaboration environments to enable discovery and access, interpretation and analysis, creation and sharing of knowledge" [8].

\section{Knowledge Center Genesis}

"The most significant innovation enables the realization of far greater human potential. The catalyst of such creativity in higher education is the acquisition of new knowledge and the living of new experiences. Then, within innovation and incubation environments, new thinking enriches knowledge handed down from previous generations, enlivens contemporary lives and informs future growth" [8]. In this spirit, the University for Business and Technology aims to create an intentional campus learning ecosystem - a Knowledge Center comprised of systems, services, facilities and resources - through reinventing and redesigning UBT Libraries. Anticipated outcomes recognize the synergistic potential of ensuring robust discovery and access to academic publisher content (through the university library) and local intellectual content (in an institutional repository). These innovations reflect worldwide transformation of academic libraries into fullservice learning, research, and project spaces.

The organizational knowledge vision for the Center was advanced in spring semester 2017 during a graduate 'soft' systems modelling course. Using human-centered methodologies, international higher education collaborators [10] worked together to design curriculum activities [11] for 
envisioning virtual spaces and physical places for and with Kosovo students, professors, and staff. In a 'learn by doing' fashion, students generated design recommendations, which prioritized co-creation of a digital environment to advance local knowledge curation, preservation, and access. They also recognized the importance of cultural practices, including acquisition, organization, and dissemination workflows, to promote student and faculty curation, interpretation, and usage of student research projects, faculty research papers, and community research reports. Finally, students suggested intensifying efforts to enable online access to published academic scholarship through an online public access catalogue (for books) and aggregated academic publisher databases (for journals).

\section{Center Concept Origins}

Early design thinking about the University for Business and Technology Knowledge Center concept is grounded in Peter Checkland's Soft Systems Methodology processes [3 -6] and Christine Bruce's Informed learning theories [1-2]. In combination, this antecedent scholarship from England and Australia, amplified in Sweden and the United States [12], now furthers systems design and knowledge management in the UBT Knowledge Center in Kosovo. These founding ideas aim to further information exchange, reflective dialogue, knowledge creation, and conceptual change [9]. Graduate students in a 6 -credit graduate level Information Systems Analysis, Design, and Modelling course at the Pristina campus served as initial co-design practitioners, researchers, and consultants for the UBT Knowledge Center, utilizing these ideas.

Throughout, Soft Systems Methodology tools and techniques guided course participants' exploration of essential questions related to the why, what, and how [7,

219f] of 'the problematical situation'. Co-design process was facilitated by guest professors from Sweden and the United States and informed through course presentations and conversations with UBT academic and technology leaders. Student projects applied SSM tools to create models and generate recommendations on various dimensions of the Knowledge Center idea.

Project \#1 choose to focus on the technological part of the problematical situation. Group members identified six perspectives - from students' experiences - to further explore using SSM models. One viewpoint related to students' wishes for access to free and credible data and, relatedly, a second perspective acknowledged students' desire to collaborate in research projects and therefore contribute to production of freely available credible content. From the position of librarians, another perspective prioritized the organization of content. Two other perspectives, reflective of UBT information technology staff members' worldview, emphasized data center infrastructure establishment, including information security for protecting intellectual property. The sixth perspective, presented by Rektor Hajrizi, envisioned making local knowledge visible through furthering discovery of and access to research content produced by academic students and university professors on institutional, local, and international levels. He acknowledged that this necessarily required policies and procedures to collect relevant information as well as provision of a digital platform for data exchange [9].

Project \#2 expanded on the institutional role for campus libraries across the world. Team members also considered the global impact of a mature UBT Knowledge Center. Mindful of the need for phased projects, students recommended revisiting current library facility design decisions, to create more attractive and inclusive spaces for both physical and virtual technologies and services that enable information flow and knowledge exchange. This included ensuring easy access for people with disabilities [9]. 
Project \#3 imagined the UBT Knowledge Center as consisting of four pillars comprised of physical library, electronic archive (e-archive), globalization platform, and online communication. From both systems/technology and social/political perspectives, the group found the e- archive to be of greatest interest. In their drawings, the e-archive anticipates the full expression of the Rektor's vision, which enable curating, storing, and sharing local knowledge through a global platform accessible by other universities within the region and around the world [9].

\section{Synthesized Concept of the UBT Knowledge Center}

Movement toward a coherent, integrated design concept required synthesizing student teams' visions for a UBT Knowledge Center. In that spirit, the international teaching team collaborated with university leader Dr. Edmond Hajrizi to create a comprehensive conceptualization figure, depicted in the Rich Picture style, Figure 1.

The figure depicts an early rendering reflecting institutional vision, potential design, and value added. Starting at the top right corner of the figure, UBT, with its four campuses, is illustrated. As presented, UBT is located in Kosovo but functions in an international setting through its collaborators - symbolized with a globe. An arrow to the left of UBT illustrates the various disciplines and educational programs offered.

In the bottom right corner, the current physical library is depicted with its stacks of 250,000 print books, as well as its e-books and publisher databases. The librarians' present work with physical books and digital material, including cataloguing and circulation, are illustrated at the left of the sphere named 'core knowledge'.

To the left of the UBT symbol, elements of the Rektor's futuristic vision are illustrated as physical 'places and spaces' for collaboration (see the center of the figure) and repositories for students' and professors' academic work. The students' ideas about collaborative digital solutions supporting their studies and enhancing their knowledge development are also represented. 


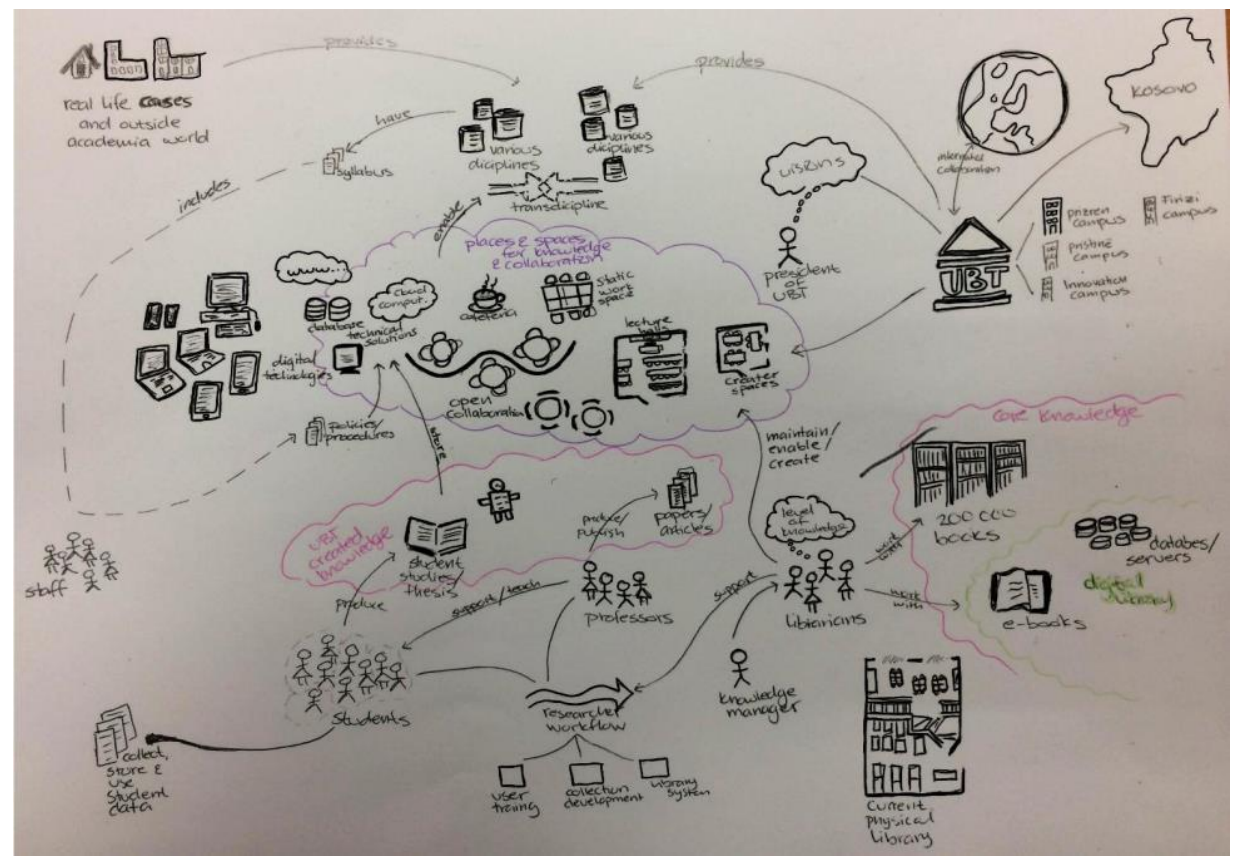

Fig. 1. Conceptualization of the UBT Knowledge Center [9]

To realize these initial design ideas, Figure 1 further acknowledges that the interior design of the library facility needs to be re- designed to open up places and spaces as well as enable mobility and flexibility. The drawing for a repository for UBT created knowledge recognizes a need for developing sustainable architecture and software. In addition, there is need for policies and guidelines (illustrated below the 'digital technological solutions' at the middle left) on how these technologies should be used to support integrity, accessibility and storage. Further, Figure 1 recognizes that the library can act as a node, but its function needs to be expanded in terms of identifying the knowledge needs as well as working with, and supporting professors and students with their research workflow (illustrated as a wavy arrow at the center bottom). This is likely to require development of staff members' level of knowledge and competence as well as establishment of a new professional position of knowledge manager.

In its fullest expression, the UBT Knowledge Center adds considerable value to the academic library, which is complemented by open spaces and collaboration places, and amplified by a UBT knowledge repository. This visioning, repurposing, and designing activities anticipate that an academic library must provide flexible, future-oriented services, resources, and expertise in remodelled spaces, enabled by ubiquitous technology and wireless internet. By realizing these anticipated 'musts', UBT will further its Knowledge Center vision, i.e., discovery and access, interpretation and analysis, and creation and sharing of knowledge. Re- invented spaces also accommodate growing demand for more flexible and collaborative spaces, reflective of $21 \mathrm{st}$ century teaching methods that engage students in active learning and group work. Project scope might also integrate food services to encourage gathering and lingering - to forge social relationships necessary for information exchange and knowledge creation - and thereby advance "knowledge management and information systems" [13]. Within this rich framework of ideas, University for Business and Technology architecture, furniture, and interior design studios will 
explore facility design modifications for the UBT Innovation Campus Library during fall semester 2017.

\section{Knowledge Center Reflections}

In setting the founding vision for University for Business and Technology in 2001, founder and President Dr. Edmond Hajrizi aimed to prepare Kosovar students to become active contributors to the society and in the workplace, within the country, the Balkans region, and beyond. Now, sixteen years later, the Knowledge Center initiative acknowledges the University's continuing responsibility to foster democratic civil society and regional economic growth, as well as further smart business practices and higher education efficiencies, through knowledge sharing for knowledge generation. In the belief that enabling educational environments advance 'learning to learn together', outcomes for the Knowledge Center promote university community members' capacity "to share what they have learned, learn what others want to share, and imagine how they might combine their talents to discover and do even more meaningful work ... for the greater good of humanity" [8].

The Knowledge Center concept appreciates the social context of learning - that knowledge is acquired and understood through action, interaction, and sharing with others, oftentimes enabled by technology. This vision thereby aligns well with other UBT innovation and incubation initiatives, which recognize that ideas, people, and technology - in relationship and through connection - enliven thinking and inform growth that activates human potential and enriches social progress. Of special significance, inclusive and participatory co-design activities will initiate and sustain working relationships among UBT faculty, staff, and students that ensure steady progress from concept to design to implementation and transformation - which animates creativity and innovation, accelerates adoption and adaption, and amplifies experience and knowledge.

Forthcoming activities includes workshops with UBT faculty, students and collaborators. Further, students in a master's course at Linnaeus University in Sweden will explore Knowledge Center ideas about IS/IT organizing, communicating and collaborating, in the spirit of 'learn by doing', to meet their course learning outcomes. Thus, these students too will contribute to - and learn from - realization of the bold Knowledge Center vision as they add - from afar - their ideas about what is both feasible and desirable to implement in the Kosovar setting. Such mutual benefit is a fitting collaborative design outcome because, finally, the UBT "initiative acknowledges that societal progress, whether local or global, ultimately depends on catalyzing, fortifying, and affirming human inquiry ... working in a global marketplace and living in a global society" [8]. Note: This international collaboration is funded in part by a 2017 Fulbright Specialist Program award from the J. William Fulbright Foreign Scholarship Board, United States of America. 


\section{References}

1. Bruce, C. S.: Informed learning. Association of College and Research Libraries, American Library Association, Chicago, IL (2008)

2. Bruce, C., Partridge, H., Hughes, H., Davis, K., Stoodley, I. (eds.): Information Experience. Approaches to Theory and Practice. (Library and Information Science, 9), Emerald, Bingley, United Kingdom (2014)

3. Checkland, P.: Systems Thinking, Systems Practice. John Wiley \& Sons, Chichester, United Kingdom (1981)

4. Checkland, P.: Autobiographical Retrospectives: Learning your way to 'action to improve'

5. - the development of soft systems thinking and soft thinking methodology. International Journal of General Systems, Vol. 40:5 (2011) pp. 487-512

6. Checkland, P., Holwell, S.: Information, Systems, and Information Systems: Making sense of the field. John Wiley \& Sons, Chichester, United Kingdom (1998)

7. Checkland, P., Poulter, J.: Learning for Action: A short definitive account of Soft Systems Methodology and its use for practitioners, teachers and students. John Wiley \& Sons, Chichester, United Kingdom (2006)

8. Checkland, P., Poulter J.: Soft Systems Methodology. In: Reinhold, M., Holwell, S. (eds.): Systems Approaches to Managing Change. A practical guide. Springer, London (2010) pp. 191-242

9. Hajrizi, E., Mirijamdotter, A., Salavati, S., Somerville, M. M.: University for Business and

10. Technology University Libraries and Knowledge Center. A concept paper. In: Fostering the As-A-Service Economy. International Conference Proceedings - Information Systems and Technology Innovations 2017 (ISTI 2017), Tirana, Albania. (2017) (in press)

11. Mirijamdotter, A., Somerville, M. M., Salavati, S., Hajrizi, E.: University for Business and

12. Technology Knowledge Center. Making local knowledge visible. In: Proceedings of the 61st Annual Meeting of the International Society for the Systems Sciences (ISSS). From Science to Systemic Solutions - Systems Thinking for Everyone, Vienna, Austria (2017) (in press)

13. Somerville, M. M.: Informed Systems for participatory organizations. Contributions from international researchers. In: Finken, S., Mörtberg, C., Mirijamdotter, A. (eds.)

Organizing, Designing, and Managing. 18th Dilemmas International Research Conference, Växjö, Sweden (2015a) Available: https://open.lnu.se/index.php/dilemmas/article/view/537

14. Somerville, M. M.: Informed Systems: Organizational design for learning in action. Chandos Publishing, a subsidiary of Elsevier, Oxford, England (2015b)

15. Somerville, M. M., Mirijamdotter, A.: Information experiences in the workplace.

16. Foundations for an Informed Systems Approach. In: Bruce, C., Partridge, H., Hughes, H., Davis, K., Stoodley, I. (eds.) Information Experience. Approaches to Theory and Practice (Library and Information Science, Vol. 9), Emerald, Bingley, United Kingdom (2014) pp. 203-220

17. Xhemaili, S.: The Role of Knowledge Management in the Information System. In: University for Business and Technology International Conference Proceedings, Pristina, Kosovo (2014) 